\title{
Mortality study among workers producing ferroalloys and stainless steel in France
}

\author{
Jean J Moulin, Pierre Portefaix, Pascal Wild, Jean M Mur, Georges Smagghe, Bernard Mantout
}

Abstract

A mortality study was carried out among the workers of a plant that had produced ferrochromium and stainless steel, and was still producing stainless steel, in order to determine whether exposure to chromium compounds, to nickel compounds, and to polycyclic aromatic hydrocarbons (PAH) could result in a risk of lung cancer for the exposed workers. The cohort comprised 2269 men whose vital status were recorded between 1 January 1952 and 31 December 1982. The smoking habits of $67 \%$ of the cohort members were known from medical records. The observed numbers of deaths were compared with the expected ones based on national rates with adjustment for age, sex, and calendar time. A low mortality, achieving statistical significance, was found from all causes (observed $=137$, standardised mortality ratio $(S M R)=0.82$ ) and from benign respiratory diseases (observed $=$ one, $\mathbf{S M R}=$ $0 \cdot 15)$. With regard to mortality from lung cancer, a non-significant excess appeared in the whole cohort (observed $=12, S M R=1 \cdot 40$ ). Among the exposed workers, however, a significant lung cancer excess was found (observed $=11, S M R=2 \cdot 04$ ) that contrasted with a low SMR (0.32) in the non-exposed group. This excess is unlikely to be explained by smoking, as the tobacco consumption of these two groups was similar. No trend was observed for mortality from lung cancer either according to time since first exposure, or according to duration of exposure. A nested case-control study clearly suggested that this excess of deaths from lung cancer was attributable to former PAH exposures in the ferrochromium production workshops rather than to exposures in the stainless steel manufacturing areas.

French National Institute for Research and Safety (INRS), Department of Epidemiology-BP 27, 54501 Vandoeuvre les Nancy Cédex, France

J J Moulin, P Wild, J M Mur

Ugine ACG, DASA, 4 Place de la Pyramide, Cédex 33, 92070 Paris La Defense, France

P Portefaix, G Smagghe, B Mantout
The production of alloyed and stainless steels, due to a growing demand for steel with specific properties, has resulted in the occurrence of nickel and chromium compounds in the atmosphere of several workplaces. The toxic effects of these metals or of their compounds, particularly their carcinogenicity, have been demonstrated for some occupations such as bichromate and chromate pigment production, chromium plating, nickel refining operations, and, to a lesser extent, production of chromium alloys. ${ }^{1}$ With regard to stainless steel welders, publications provide heterogeneous data as the risks of lung cancer suggested by Becker et $a l^{2}$ and by Sjögren et $a^{3}$ among welders exposed to hexavalent chromium have not been confirmed by a recent European study. ${ }^{4}$

The manufacture of ferroalloys results in a complex mixture of particles, fumes, and chemicals, ${ }^{5-10}$ among which nickel and trivalent and hexavalent chromium are of particular interest for this study. Such exposure has also been found in stainless steel manufacturing and grinding, as well as in stainless steel welding. ${ }^{8}$ The relative proportions of these airborne compounds depend on which alloy is produced and on which production process is employed. As well as exposure to these metals, ferrochromium manufacturing requires the heating of carbon electrodes, which releases combustion products containing polycyclic aromatic hydrocarbons (PAH) whose carcinogenicity for humans has been well established. ${ }^{1}$

Following previous mortality or cancer incidence studies carried out in the ferroalloy ${ }^{51112}$ or stainless steel industries, ${ }^{613-15}$ the present mortality study was set up in a French factory concerned with the production of ferrochromium and stainless steel. It was aimed at assessing a possible risk of lung cancer for the workers associated with this production.

\section{Material and methods}

PRODUCTION PROCESSES AND EXPOSURES

The factory was set up in 1952. It is situated in south eastern France in a non-industrialised area. The production of different varieties of ferrochromium started in 1952 and continued until 1982 when this production ceased. The processes consisted of the electrothermal reduction of quartz and chromium ore with coke. For this purpose the plant used Söderberg electrodes in arc furnaces. The produc- 
tion of stainless steel, which started in 1958, is still going on today. This process requires the electrothermal casting of scrap, mild and stainless steel, nickel, ferrochromium, and other ferroalloys depending on which alloy is to be produced, and uses furnaces equipped with exhaust ventilation.

Although no previous or contemporary data are available on the composition of dust and fumes, a qualitative assessment can be made of the main pollutants of the plant-namely, chromium compounds, nickel compounds, and PAH. The ferrochromium production workshops were polluted by PAH owing to the combustion of coke and of the Söderberg electrodes, and by chromium which could have been in the metallic, trivalent, or hexavalent forms ${ }^{8}$ It is noteworthy that several improvements in the working conditions (exhaust ventilation) and the industrial processes have occurred since 1952 and that chemical exposures are, therefore, likely to have been higher in the past than in recent times.

Furthermore, the pollution in the stainless steel production workshops did not contain PAH as graphite electrodes were used. The processes carried out in these workshops probably results in exposures to chromium compounds (metallic, trivalent, hexavalent) and to nickel at relatively low concentrations as furnaces were equipped with exhaust ventilation.

Irrespective of the exposures to metals and $\mathrm{PAH}$, a small number of workers in the ferrochromium production workshops were exposed to silica owing to the use of quartz and some others were exposed to asbestos employed in the maintenance of furnaces.

\section{COHORT AND DATA COLLECTION}

The cohort under study was defined as all men employed for at least one year between 1 January 1952 when the factory was set up and 31 December 1982. For each man the follow up for mortality lasted from the date of first employment to 31 December 1982. The factory provided individual records for all the cohort members, which included names, dates and places of birth, and periods of employment. The mortality of the workers was traced through the registry offices of the birthplaces for people born in France. Foreigners whose vital status were unknown by the administrators at the factory were considered as lost to follow up when they left the factory. Due to specific French confidentiality constraints, the causes of death were not available from death certificates. For this reason, the causes of death were ascertained from general practitioners or from hospital records. Also, the medical records of the plant provided data on the smoking habits of the workers taking into account never smokers, ex-smokers, and current smokers ( $<20$ cigarettes a day, 20 cigarettes a day, $>20$ cigarettes a day, and unknown amount). With regard to smoking habits, data had been collected by the same occupational physician during the period under consideration when the workers? underwent their clinical examinations. All the available data thus gathered were taken into account ino order to assess the tobacco consumption of the음 workers.

Concerning occupational exposure, individual job $\overrightarrow{\mathrm{Q}}$ histories were taken into account after the date of first employment in the factory. The data were available, ${ }^{\infty}$ however, only in the form of "exposed" or "non-. exposed" periods for each man, with the dates of the $\overrightarrow{\vec{H}}$ beginning and the end of these periods. The termo "exposed" means to have been employed for at least one year either in the workshops producing ferro- 3 chromium, or in the workshops producing stainless $A$ steel. Due to the fact that PAH were present only in 0 the ferrochromium workshops, however, this information did not enable the group exposed to PAH to be studied separately. In order to take into account 음 exposure to PAH a nested case-control study wasconducted. For this purpose, the job histories of cases and controls were traced in detail.

\section{STATISTICAL METHODS}

Two main statistical methods were used, an external comparison with the French general population ando an internal comparison by means of the nested casecontrol study. For the external comparison, the expected numbers of deaths were computed by multiplying the person-years of the cohort within each five year age category for each of the years from $\overrightarrow{\overrightarrow{0}}$ 1952 to 1982 by the male, cause, age, and calendar year specific national death rates provided by the French National Institute for Statistics and Economic Studies (INSEE) and the French National Institute for Medical Research and Health 3 (INSERM). ${ }^{1617}$ The procedure described by Coleman et al $^{18}$ was used to calculate person-years, expected numbers of deaths by causes, and ratios 0 between observed and expected numbers (standard- $₹$ ised mortality ratios (SMRs)). Ninety five per cent응 confidence intervals $(95 \% \mathrm{CI})$ for the SMR values $>$ were computed assuming a Poisson distribution.

As mentioned above, a case-control study was carried out in the cohort in order to improve the . analysis of exposure to PAH. The cases were the $N$ workers who died from lung cancer. Five controls for $N$ each case were chosen at random from within the cohort, and individually matched to the cases by year of birth. Each control worker had to be still alive and ${ }_{\Phi}^{\widetilde{C}}$ free of lung cancer at the date of death of the $\stackrel{?}{+}$ corresponding case. For each case and control, the 0 exposure histories were assessed to identify those who had been exposed to PAH. Three categories $\overparen{D}$ were thus defined-those definitely exposed to PAH $\mathbb{\otimes}$ and to chromium compounds; those who had been possibly or intermittently exposed to PAH and to chromium compounds, such as maintenance 
Table 1 Results of follow up of workers

\begin{tabular}{lc}
\hline & No of workers \\
\hline Total cohort: & 2269 \\
Still alive & 2100 \\
Dead & 137 \\
Lost to follow up & 32 \\
Still active & 1114 \\
Exposed workers & 1718 \\
Workers born abroad & 342 \\
Number of person-years & 33945 \\
\hline
\end{tabular}

*Workers employed for at least one year in the ferrochromium or stainless steel production workshops.

workers; and those exclusively exposed to chromium and nickel compounds.

The results of this analysis are given in the form of odds ratios (ORs) of exposed subjects as compared to those who were never exposed. The OR estimates and their variance were computed using the conditional logistic regression fitted by the maximum likelihood method. ${ }^{19}$

\section{Results}

Of the 2294 available workers, 25 were excluded because of incomplete data on employment, leading to a final study of 2269 records (table 1). At the end of the follow up (31 December 1982) 2100 workers were alive and 1114 were still active in the factory. Thirty two subjects who were lost to follow up during the survey period contributed to person-years from the date of first employment to the date of end of employment. The number of deaths was 137 among which two causes remained unknown. The number of workers exposed to combinations of PAH, nickel, and chromium compounds-that is, employed for at least one year in workshops producing ferro- chromium stainless steel-was $1718(75 \cdot 7 \%$ of the whole study population).

The overall mortality (137 deaths) was significantly lower than that expected $(S M R=0.82)$ on the basis of the national rates (table 2). The SMRs were close to one for circulatory diseases $(\mathrm{SMR}=$ $1.04)$, for accidents and suicide $(S M R=0.94)$, and for all cancers $(S M R=0.91)$. A significantly low SMR, however, was found for mortality due to benign respiratory diseases (observed $=$ one, SMR $=0.15)$. With regard to cancer sites, a nonsignificant excess was observed for lung cancer (observed $=12$, SMR $=1.40$ ), for stomach cancer (observed = four, SMR = 1.57), for prostate cancer (observed = two, SMR = 1.93), and for brain tumours (observed = three, $S M R=3.56$ ).

Table 3 gives the mortality data for exposed and non-exposed workers. The main result was the significant excess of lung cancer among the exposed workers (observed $=11, \quad S M R=2.04$ ), which contrasted with a low mortality from this disease in the non-exposed group (observed = one, SMR $=0.32$ ). Deaths from stomach cancer in the cohort were concentrated in the exposed group, leading to a non-significant SMR of $2 \cdot 75$. No other appreciable differences were noted.

Table 4 gives the results of the survey concerning tobacco consumption. The smoking habits of $66.7 \%$ of the exposed workers and of $62.5 \%$ of the nonexposed ones were known; thus the information available for the two groups was similar. Likewise, among workers whose smoking habits were known, only slight differences appeared with $25.8 \%$ of never smokers in the exposed group against $21.4 \%$ in the other, and $\mathbf{7 4 . 2} \%$ against $\mathbf{7 8 . 5} \%$ for ever smokers. The amount of tobacco smoked by the current

Table 2 Observed (obs) and expected (exp) deaths, SMRs, and 95\% CIs in study population; 2269 workers throughout period 1952-82

\begin{tabular}{|c|c|c|c|c|c|}
\hline Cause of death ${ }^{\star}$ & & Obs & Exp† & $S M R$ & $95 \% C I$ \\
\hline $\begin{array}{l}\text { All causes } \\
\text { Unknown causes } \\
\text { Circulatory system } \\
\text { Respiratory system } \\
\text { Cirrhosis of the liver } \\
\text { Accidents and violence }\end{array}$ & $\begin{array}{r}(000-999) \\
(390-458) \\
(460-519) \\
(571) \\
(E 800-E 999)\end{array}$ & $\begin{array}{r}137 \\
2 \\
37 \\
1 \\
8 \\
36\end{array}$ & $\begin{array}{r}166 \cdot 91 \\
35 \cdot 51 \\
6 \cdot 46 \\
11 \cdot 61 \\
38 \cdot 20\end{array}$ & $\begin{array}{l}0.82 \\
1.04 \\
0.15 \\
0.69 \\
0.94\end{array}$ & $\begin{array}{l}0.69-0.97 \\
0.73-1.44 \\
0.00-0.86 \\
0.30-1.36 \\
0.66-1.30\end{array}$ \\
\hline $\begin{array}{l}\text { All malignant neoplasms: } \\
\text { Buccal cavity, pharynx, larynx } \\
\text { Oesophagus } \\
\text { Stomach } \\
\text { Intestine except rectum } \\
\text { Rectum } \\
\text { Pancreas } \\
\text { Trachea, bronchus, and lung } \\
\text { Bladder } \\
\text { Prostate } \\
\text { Brain } \\
\text { Sarcoma } \\
\text { Lymphoma } \\
\text { Leukaemia }\end{array}$ & $\begin{array}{r}(140-207) \\
(140-149,161) \\
(150) \\
(151) \\
(152-153) \\
(154) \\
(157) \\
(162) \\
(188) \\
(185) \\
(191) \\
(170-171) \\
(200) \\
(204-207)\end{array}$ & $\begin{array}{r}38 \\
7 \\
0 \\
4 \\
0 \\
0 \\
0 \\
12 \\
0 \\
2 \\
3 \\
0 \\
1 \\
0\end{array}$ & $\begin{array}{r}41.95 \\
7.68 \\
3.45 \\
2.54 \\
2.02 \\
1.12 \\
1.31 \\
8.56 \\
0.88 \\
1.04 \\
0.84 \\
0.62 \\
1.60 \\
1.55\end{array}$ & $\begin{array}{l}0.91 \\
0.91 \\
0.00 \\
1.57 \\
0.00 \\
0.00 \\
0.00 \\
1.40 \\
0.00 \\
1.93 \\
3.56 \\
0.00 \\
0.62 \\
0.00\end{array}$ & $\begin{array}{l}0.64-1.24 \\
0.37-1.88 \\
0.00-1.07 \\
0.43-4.03 \\
0.00-1.83 \\
0.00-3.29 \\
0.00-2.82 \\
0.72-2.45 \\
0.00-4.19 \\
0.23-6.94 \\
0.74-10.44 \\
0.00-5.95 \\
0.02-3.48 \\
0.00-2.38\end{array}$ \\
\hline
\end{tabular}

*International Classification of Diseases -8 th revision in parentheses.

$\dagger$ The expected numbers were calculated using national death rates with adjustment for sex, age, and calendar time. 
Table 3 Observed (obs) and expected (exp) deaths, SMRs and 95\% CIs among exposed and non-exposed workers

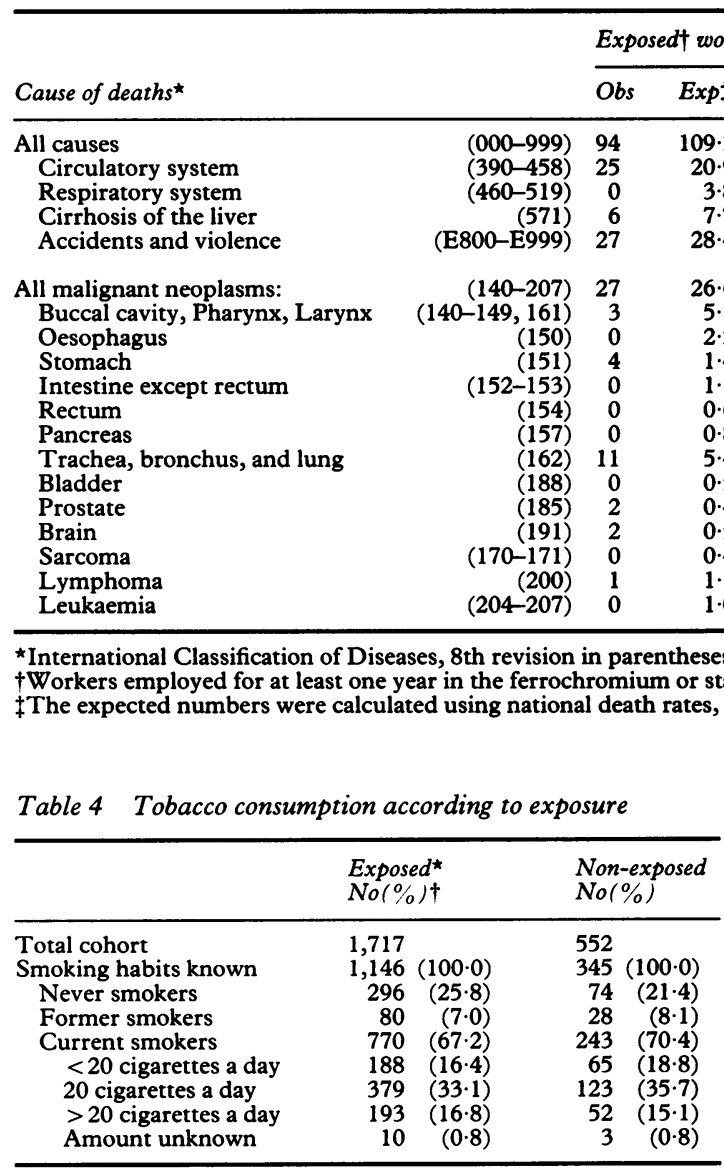

*Workers employed for at least one year in the ferrochromium or stainless steel production workshops.

t" ${ }_{0}$ Of those with smoking habits known.

smokers was also similar between the groups. Owing to the fact that nearly one third of the information was lacking, smoking habits were not taken into account in the computation of SMRs.

To establish whether there was a dose response relation with lung cancer, the duration of exposure was used as a parameter (table 5). No clear dose response relation appeared as SMRs were of the same magnitude for the lowest and for the highest exposure categories. Similarly, time from first

exposure was used to determine whether there was aO latent period for the risk of lung cancer (table 5). Thes mortality was significantly increased for the inter- $-\frac{}{\circ}$ mediate duration of latency, but the lowest SMR appeared for the longest latency period.

In order to take into account the improvements of the working conditions and of the industrial proces- $\frac{3}{3}$ ses which occurred during the period 1952-82, a $\supset$ relation was sought between mortality from lungo cancer and the dates of first employment in the factory (table 6). In spite of random fluctuations due to small numbers, a trend was apparent as all deaths from lung cancer occurred among people who started employment before 1964. This led to a significant excess for this category.

To determine whether PAH exposures could have been responsible for part or for all the excess of lung cancer found among the exposed workers, the case $-\frac{\rightarrow}{2}$ control study was carried out using 58 controls selected from the cohort matched with the 12 cases of $N$ deaths from lung cancer. The theoretical number of 60 controls could not be reached because of the small 0 number of workers in one year of birth. The analysis $\omega$ gave the ORs using two different procedures. Firstly, the subjects who had been possibly or intermittently을

Table 5 Observed (obs) and expected (exp) deaths, SMRs, and 95\% CIs for mortality from lung cancer according to duration of exposure and to time since first exposure

\begin{tabular}{|c|c|c|c|c|c|c|c|}
\hline Duration of exposure ${ }^{\star}$ & Obs/exp & $S M R$ & $95 \% C I$ & Time from first exposure & Obs/exp & $S M R$ & $95 \% C I$ \\
\hline $\begin{array}{l}\text { Non-exposed } \\
1-9 \text { years } \\
\geq 10 \text { years }\end{array}$ & $\begin{array}{l}1 / 3 \cdot 15 \\
6 / 2 \cdot 65 \\
5 / 2 \cdot 74\end{array}$ & $\begin{array}{l}0 \cdot 32 \\
2 \cdot 26 \\
1 \cdot 82\end{array}$ & $\begin{array}{l}0.01-1.77 \\
0.83-4.93 \\
0.59-4.26\end{array}$ & $\begin{array}{l}1-9 \text { years } \\
10-19 \text { years } \\
\geq 20 \text { years }\end{array}$ & $\begin{array}{l}2 / 1 \cdot 37 \\
7 / 2 \cdot 18 \\
2 / 1 \cdot 84\end{array}$ & $\begin{array}{l}1.46 \\
3.20 \\
1.08\end{array}$ & $\begin{array}{l}0 \cdot 18-5 \cdot 27 \\
1 \cdot 29-6 \cdot 61 \\
0 \cdot 13-3 \cdot 92\end{array}$ \\
\hline
\end{tabular}

*Workers employed for at least one year in the ferrochromium or stainless steel production workshops. 
Table 6 Observed (obs) and expected (exp) deaths, SMRs and $95 \%$ CIs for mortality from lung cancer according to period of first exposure

\begin{tabular}{lrll}
\hline Period of first exposure & Obs/exp & SMR & $95 \%$ CI \\
\hline$\leq 1954$ & $3 / 0.76$ & 3.95 & $0 \cdot 82-11.54$ \\
$1955-9$ & $4 / 2.49$ & 1.61 & $0.44-4 \cdot 11$ \\
$1960-4$ & $4 / 0.86$ & 4.65 & $1 \cdot 27-11.91$ \\
$\geq 1965$ & $0 / 1 \cdot 29$ & 0.00 & $0.00-2.86$ \\
Total 1952-64 & $11 / 4 \cdot 11$ & 2.68 & $1 \cdot 34-4.79$ \\
Total 1952-82 & $11 / 5.40$ & 2.04 & $1.02-3.64$ \\
\hline
\end{tabular}

*Workers employed for at least one year in the ferrochromium or stainless steel production workshops.

exposed to PAH were confounded with those whose exposure to PAH was certain. Secondly, they were considered as non-exposed workers. This led to two sets of ORs (table 7). Under the first assumption the ORs were $7 \cdot 21$ for all the exposed workers as compared with the non-exposed ones, 3.36 for those exclusively exposed to chromium or nickel compounds, or both, and 4.51 for PAH exposed employees, only the last value being statistically significant. Under the second hypothesis-that is, considering workers possibly or intermittently exposed as non-exposed-the corresponding OR values were $6 \cdot 72,2 \cdot 75$, and $14 \cdot 86$, again only the last one being statistically significant.

\section{Discussion}

In a previous study on incidence of cancer carried out by Langard $e t$ al, an excess of lung cancer was found in workers concerned with ferrochromium production. ${ }^{7}$ The observed number was seven and $3 \cdot 1$ were expected from national or 1.8 from local reference rates, giving SMRs of 2.26 and 3.89 . Also, the authors mentioned an internal reference consisting of non-exposed workers whose SMR for lung cancer was 0.31 using national rates. This low value was contrasted with the value of $2 \cdot 26$ for ferrochromium production workers. It is worth noticing that in the present study the SMRs for lung cancer were similar for the exposed and non-exposed workers (2.04 and 0.32). In a study by Axelsson et al among ferro- chromium workers, the observed excess of lung cancer among maintenance workers was attributed to asbestos exposure (four observed $v$ one expected). ${ }^{5}$ No lung cancer excess was found by Kjuus et al among ferrosilicon and ferromanganese workers. ${ }^{11}$ Calcium carbide workers have been studied by Kjuus et $a .^{12}$ The incidence of lung cancer was slightly increased among furnace and maintenance workers, which could be explained by exposures to PAH or asbestos.

Four studies have been published concerning possible risks of cancer associated with exposure to nickel compounds in nickel alloy factories. ${ }^{613-15} \mathrm{~A}$ significant excess of lung cancer was observed by Cornell and Landis ${ }^{14}$ in the $\geq 65$ age group (SMR $=1.48)$, along with a low SMR in the 40-64 age group ( $S M R=0 \cdot 80$ ). A significantly increased mortality from lung cancer was also noted by Redmond $^{15}$ for men employed in maintenance categories whose exposure to nickel was unclear $(S M R=1.30)$. Lastly, in an extensive study carried out among seven United States companies producing stainless steel and low nickel alloy steel, no lung cancer excess was registered in the exposed group (SMR $=0.97$ based on 218 observed deaths). ${ }^{13}$

The present study shows a significantly increased risk of lung cancer for the exposed workers. Before discussing this result some comments are required on the methods that have been used. For the calculation of the expected numbers of deaths, the national death rates were used as an external reference, as this was the only one available. The factory is located in an area which is not industrialised and where death rates, for this reason, may have been lower than the national ones. This assumption, the accuracy of which cannot be tested, may have accounted for a part of the overall significantly low mortality rate observed in the cohort (SMR $=0.82)$. Clearly, a "healthy worker effect" could be an additional explanation for this low overall mortality. With regard to mortality from lung cancer, an obvious geographical variation exists in France according to areas as shown by Rezvani et al. ${ }^{20}$ These authors indicate that, for the period $1971-78$, the lung cancer

Table 7 Case-control study (12 cases $v 58$ controls): numbers of cases and controls, (ORs) and 95\% CIs according to different definitions of exposure taking into account exposure to polycyclic aromatic hydrocarbons (PAHs)

\begin{tabular}{|c|c|c|c|c|c|c|c|c|}
\hline \multirow[b]{2}{*}{ Exposure } & \multicolumn{4}{|c|}{ First analysis } & \multicolumn{4}{|c|}{ Second analysis $\dagger$} \\
\hline & Cases & Controls & $O R$ & $95 \% C I$ & Cases & Controls & $O R$ & $95 \% \mathrm{CI}$ \\
\hline Non-exposed workers & 1 & 21 & 1.00 & - & 1 & 22 & 1.00 & - \\
\hline $\begin{array}{l}\text { Exposed workers: } \ddagger \\
\text { Exclusive exposure to }\end{array}$ & 11 & 37 & $7 \cdot 21$ & $0 \cdot 84-61 \cdot 70$ & 11 & 36 & $6 \cdot 72 \S$ & $0 \cdot 81-55 \cdot 70$ \\
\hline $\begin{array}{l}\text { Cr and/or Nil compounds } \\
\text { Exposure to PAH }\end{array}$ & $\begin{array}{l}4 \\
7\end{array}$ & $\begin{array}{l}25 \\
12\end{array}$ & $\begin{array}{l}3 \cdot 36 \S \\
4 \cdot 51\end{array}$ & $\begin{array}{l}0.35-32 \cdot 40 \\
1 \cdot 28-15.94\end{array}$ & $\begin{array}{l}4 \\
7\end{array}$ & $\begin{array}{r}32 \\
4\end{array}$ & $\begin{array}{l}2.75 \S \\
14.86\end{array}$ & $\begin{array}{l}0 \cdot 29-26 \cdot 30 \\
3 \cdot 04-72 \cdot 52\end{array}$ \\
\hline
\end{tabular}

*Workers whose exposure to PAH and chromium compounds had been possible or intermittent were considered as exposed to PAH. +Workers whose exposure to PAH and chromium compounds had been possible or intermittent were considered as non-exposed to PAH. $\$$ Workers employed for at least one year in the ferrochromium or stainless steel production workshops.

$\S$ Crude OR (matching was not carried out because of the small numbers). 
SMR for men of the county where the factory is located was unity using national rates as a reference. Therefore, national rates are likely to be valid in assessing the lung cancer risks in the factory under consideration.

The French legislation set up to protect individual liberty does not allow death certificates to be read. For this reason, the causes of death must be retrospectively sought in hospital files or general practitioners' records; the causes of death thus collected (observed numbers) might have been different from the causes which were used for the calculation of expected numbers (the national death rates resulting from the coding of anonymous death certificates). This discrepancy was unlikely to exist for cancers that are rather well defined diseases or for violent causes, but it might have occurred for other causes such as cardiovascular or non-malignant respiratory diseases. This bias, the magnitude of which cannot be assessed, may account for a part of the significantly low mortality due to non-malignant respiratory disease $(S M R=0.15)$ and the higher SMR value due to cardiovascular disease $(S M R=1.04)$.

An estimation of the excess of mortality from lung cancer among the exposed workers with the nonexposed group as an internal reference as proposed by Langard et al in their aforementioned paper. ${ }^{7}$ This would give a relative risk of $2.04 / 0.32=6.38$ for exposed workers. Such an assessment, however, is unlikely to be relevant because the age distribution of the two groups were different; thus this simple SMR is not valid. ${ }^{21}$ On the other hand, the use of this internal reference is relevant in evaluation of the possible role of smoking in the excess of lung cancer. Despite the fact that the degree of smoking was unknown for $34.3 \%$ of the cohort members, table 4 clearly shows that the two groups were unlikely to differ according to smoking habits. This information on smoking habits, which is often lacking in historical cohort studies, ${ }^{22}$ suggests that smoking did not confound the result of the present study. The same conclusion could be drawn when taking into account the fact that other tobacco related cancers-for example, cancers of the buccal cavity, pharynx, and laryn $\mathrm{x}$ - give rise to an exposed/non-exposed pattern opposite to that of lung cancer.

The analysis failed to establish a clear relation between mortality from lung cancer and either duration of exposure or time elapsed since first exposure. This lack of relation appears to rule out the responsibility of occupational exposures in mortality from lung cancer. ${ }^{23}$ Although this assessment is accurate, the statistical power of the study should be taken into account. Indeed, a simulation showed that given a type I error $(\alpha)$ of 0.05 , the probability of detecting a significant trend with SMRs of $0.9,1.5$, and 2.0 for non-exposed, exposed 1-9 years, and exposed $\geq 10$ years, was only $20 \%$. This rather small probability suggests that the lack of relation with the duration of exposure could be explained by thes? limited statistical power of the study. This lack ofo relation could also be explained by the fact that the definition of exposure included all workers ever employed in the ferrochromium or stainless steet workshops. This definition may be inadequate if then risk of lung cancer was in fact due exclusively to exposure to PAH.

The case control study enabled the exposure to $\mathrm{PAH}$ and chromium compounds in ferrochromiumo workshops to be taken into account. The ORs for all ${ }_{\mathbb{D}}^{-}$ the exposed workers (ferrochromium and stainless steel) were 7.21 and 6.72 , depending on whether the possibly or intermittently exposed subjects wereo considered as exposed or non-exposed. It is note- $-\mathrm{W}$ worthy that these figures agree with the relative risk calculated by dividing the SMRs of these two groups 5 $(6 \cdot 38)$. Such a similarity, which was expected as we have carried out two different analyses (externale reference with SMRs and internal reference with ORs) of the same cohort, underlines the consistency $\stackrel{\text { ? }}{9}$ of these two statistical procedures. As regards $\vec{e}$ workers exclusively exposed to nickel or chromium? compounds, or both, no statistically significant ORswere observed. On the contrary, irrespective of the way the possibly or intermittently exposed subjects were considered, the ORs were always significantly@ raised for workers exposed to PAH in ferrochromium $\bar{D}$ workshops. These results agree with the significantly high SMRs observed in the case of people hiredo during the early periods (table 6 ) when PAH pollution was likely to be at its highest in ferrochromium workshops.

In conclusion, this mortality study throughout the period 1952-82 established a statistically significant 3 excess of deaths from lung cancer among workers in $\frac{5}{3}$ the production of ferrochromium and stainless steel. considered together. No dose response relation was $\varrho$ seen with the duration of exposure, nor with time elapsed since first exposure. The risk of lung cancer, 을 however, seemed to be attributable to earlier $>$ exposures. An additional case-control study conduc-ㅡ. ted within the cohort showed that this risk of lung N cancer was related to ferrochromium producing workshops in particular. On the other hand, the risks 0 seen for the stainless steel production workers were $\omega$ not statistically significant.

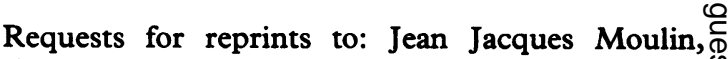
INRS, BP 27-54501 Vandoeuvre Cédex, France.

1 International Agency for Research on Cancer. Overall Evalua- $\bar{T}$ tions of Carcinogenicity: An updating of IARC Monographs, $\frac{\vec{P}}{\mathrm{C}}$ Vols 1 to 42. Supplement 7. Lyon: IARC, 1987.

2 Becker N, Claude J, Frentzel-Beyme R. Cancer risk of arc $\frac{\vec{D}}{(1)}$ welders exposed to fumes containing chromium and nickel. @ Scand $J$ Work Environ Health 1985;11:75-82.

3 Sjögren B, Gustavsson A, Hedström L. Mortality in two cohorts of welders exposed to high and low levels of hexavalent chromium. Scand J Work Environ Health 1987;13:247-51. 
4 Simonato L, Winkelmann R, Ferro G, Saracci R, Charnay N. Report of a mortality and cancer incidence follow-up of an historical cohort of European welders. Lyon: International Agency for Research on Cancer, 1989. (IARC internal report 89/003.)

5 Axelsson G, Rylander R, Schmidt A. Mortality and incidence of tumours among ferrochromium workers. $\mathrm{Br} \mathrm{J}$ Ind Med 1980;37:121-7.

6 Cox JE, Doll R, Scott WA, Smith S. Mortality of nickel workers: experience of men working with metallic nickel. $\mathrm{Br} J$ Ind Med 1981;38:235-9.

7 Langard S, Andersen AA, Gylseth B. Incidence of cancer among ferrochromium and ferrosilicon workers. $\mathrm{Br} J$ Ind $\mathrm{Med} 1980$; 37:114-20.

8 Koponen M, Gustafsson T, Kalliomäki PL, Pyy L. Chromium and nickel aerosols in stainless steel manufacturing, grinding and welding. Am Ind Hyg Assoc J 1981;42:596-601.

9 Roberts WC. The Ferroalloy Industry. Hazards of the Alloys and Semimetallics: Part I. J Occup Med 1965;7:30-6.

10 Roberts WC. The Ferroalloy Industry. Hazards of the Alloys and Semimetallics: Part II. J Occup Med 1965;7:71-7.

11 Kjuus H, Andersen A, Langard S, Knudsen KE. Cancer incidence among workers in the Norwegian ferroalloy industry. $\mathrm{Br} J$ Ind Med 1986;43:227-36.

$12 \mathrm{Kjuus} \mathrm{H}$, Andersen $\mathrm{A}$, Langard S. Incidence of cancer among workers producing calcium carbide. $\mathrm{Br} J$ Ind Med 1986; 43:237-42.

13 Cornell RG. Mortality patterns among stainless steel workers. In: Nickel in the human environment. Lyon: International Agency for Research on Cancer, 1984:65-71. (IARC sci publ No 53.)

14 Cornell RG, Landis JR. Mortality patterns among nickel/ chromium alloy foundry workers. In: Nickel in the human environment. Lyon: International Agency for Research on Cancer, 1984:87-93. (IARC sci publ No 53.)

15 Redmond CK. Site-specific cancer mortality among workers involved in the production of high nickel alloys. In: Nickel in the human environment. Lyon: International Agency for Research on Cancer, 1984:73-86. (IARC sci publ No 53.)

16 Institut National de la Statistique et des Etudes Economiques. Statistique des causes de décès. Années 1950 à 1967. Paris: INSEE, Imprimerie Nationale, 1970.

17 Institut National de la Santé et de la Recherche Médicale. Statistiques des causes médicales de décès. Paris: Les Editions INSERM, all years from 1968 to 1985 .

18 Coleman M, Douglas A, Hermon C, Peto J. Cohort study analysis with a Fortran computer program. Int J Epidemiol 1986;15:134-7.

19 Breslow NE, Day NE. The analysis of case-control studies. In: Breslow NE, Day NE, eds. Statistical methods in cancer research Vol 1. Lyon: International Agency for Research on Cancer, 1980:247-79. (IARC sci publ No 32.)

20 Rezvani A, Doyon F, Flamant R. Atlas de la mortalité par cancer en France (1971-1978). Paris: Les Editions INSERM, 1986.

21 Tsai SP, Wen CP. A review of methodological issues of the standardized mortality ratio (SMR) in occupational cohort studies. Int J Epidemiol 1986;15:8-21.

22 Marsh GM, Sachs DPL, Callahan C, Leviton LC, Ricci E, Henderson V. Direct methods of obtaining information on cigarette smoking in occupational studies. $A m \mathrm{~J}$ Ind Med 1988;13:71-103.

23 Doll R. Occupational cancer: a hazard for epidemiologists. Int J Epidemiol 1985;14:22-31.

Accepted 19 February 1990 